\title{
Post-Extubation Stridor: The Call for Objectivity
}

\author{
ROBINDER G KHEMANI \\ Department of Anesthesiology and Critical Care, University of Southern California Keck School of Medicine, Children's Hospital \\ LosAngeles,USA.RKhemani@chla.usc.edu
}

I

$\mathrm{n}$ this issue of Indian Pediatrics, Sinha, et al.(1) have reported the results of a single center randomized controlled trial evaluating aerosolized L-epinephrine vs budesonide for the treatment of post-extubation stridor. While the benefits of intravenous corticosteroids on postextubation stridor are still unclear(2), the authors propose inhaled steroids may provide similar action to intravenous steroids, with fewer side effects.

They included all recently extubated children with a stridor score $\geq 4$, based on a stridor scale identical to the Westley Croup Scale(3). While no specific exclusion criteria were listed, the 134 children categorized as "excluded" appear to simply not meet inclusion criteria. An appropriate block randomization strategy was implemented to ensure equal distribution of those with pre-existing airway disease. The study was not blinded, neither for assessment of outcome nor for analysis. Patients were randomized to receive either $1000 \mu \mathrm{g}$ of budesonide or $0.25 \mathrm{~mL}$ of $1 \%$ epinephrine. The primary outcome measure was "extubation failure," defined as a stridor score remaining $\geq 4$, renebulization, or reintubation within 24 hours of extubation. The study was designed to detect a reduction in "failure rate" from $40 \%$ to $10 \%$, a $30 \%$ absolute risk reduction, or a $75 \%$ relative risk reduction.

Overall there was no difference between budesonide and epinephrine on the primary outcome measure. While the median 2 hour stridor score was lower for those that received epinephrine compared to budesonide, this was not adjusted for multiple comparisons with repeated measures ANOVA, although the methods describe the intention to do this. While both drugs were similar in efficacy, adverse effects, and onset of action, the authors conclude epinephrine demonstrates a more sustained effect because the stridor score at 2 hours was lower. However, this trend is not evident by looking at the scores as a function of time, and without adjustment for multiple comparisons, this may be a result of chance. To their credit, they report this may not be clinically significant.

Regardless of the therapy, over $50 \%$ of patients had a stridor score $\geq 4$ within the first 24 hours of treatment, with close to $40 \%$ requiring rescue nebulization with epinephrine (both groups), and over $20 \%$ requiring re-intubation. The overall incidence of "post-extubation stridor" was $31.6 \%$. While the authors should be congratulated for attempting to attack a common and difficult problem in pediatric critical care, this study highlights the challenges surrounding post-extubation stridor. While stridor scales have been used to assess upper airway obstruction severity, they have never been validated against objective measures of upper airway obstruction such as spirometry(4), and have inconsistent inter-observer variability(5-7). The authors do not describe how many investigators evaluated stridor severity with the corresponding inter-observer reliability of the stridor scale or the internal validity of the scale if a single investigator was used. This is particularly important because the score was used both for inclusion criteria and for the assessment of outcome. While baseline "stridor scores" were similar between groups, there is only one element of this score which is specific to upper airway obstruction (inspiratory stridor), which 
carries less weight than other, less specific elements of the score. As such, this score will be elevated if children have residual respiratory, neuromuscular or neurologic disease. The use of a spontaneous breathing trial prior to extubation could have further elucidated these potential contributions. The uncertainty and variability of the stridor scale is particularly important in this study because the investigators assessing outcome were not blinded to the intervention, which could introduce bias.

While the incidence of post-extubation stridor $(31.6 \%)$ was reported as similar to other studies, the cited studies are now 18 years old. More recent estimates reveal with careful consideration of tube size, the incidence of stridor is closer to $15 \%(7,8)$. This difference can partially be explained by the inclusion of children with underlying airway anomalies (10\%). It may also be explained by the lack of objectivity and the variability of definitions of post-extubation stridor.

The study was largely underpowered, as a $30 \%$ absolute or $75 \%$ relative risk reduction is well above what most would consider clinically significant. However, there was no trend for benefit, so it is unlikely that a significant difference between treatments in the first hour was missed. Moreover, all patients who received "re-nebulization (40\%)," received racemic epinephrine at a median of 90 (60240) minutes in the budesonide group. Therefore the stridor scores after 60 minutes are difficult to interpret because $40 \%$ of the patients in the budesonide group subsequently received racemic epinephrine.

Finally, regardless of the treatment arm, approximately half of the patients did not respond to either therapy. As the authors suggest, the underlying etiology could contribute to this variability, but it is also reflects the imprecision of the evaluation of post-extubation stridor. If we are to move forward with studies on post-extubation stridor, we must have a reliable and reproducible objective outcome measure. This may include using spirometry and esophageal manometry to demonstrate flow limitation. Without this, we will not be able to identify risk factors for extubation failure from upper airway obstruction, or determine the benefits of potential therapeutics such as racemic epinephrine, inhaled or intravenous steroids, heliox, or non invasive positive pressure ventilation.

Funding: None.

Competing interests: None stated.

\section{REFERENCES}

1. Sinha A, Jayashree M, Singhi S. Aerosolized Lepinephrine vs budesonide for post-extubation stridor: A randomized controlled trial. Indian Pediatr 2010; 47: 317-322.

2. Khemani RG, Randolph A, Markovitz B. Corticosteroids for the prevention and treatment of post-extubation stridor in neonates, children and adults. Update of Cochrane Database Syst Rev 2008; 2: CD001000. Cochrane Database Syst Rev 2009; 3: CD001000.

3. Westley CR, Cotton EK, Brooks JG. Nebulized racemic epinephrine by IPPB for the treatment of croup: a double-blind study. Am J Dis Child 1978; 132: 484-487.

4. Argent AC, Newth CJ, Klein M, Argent AC, Newth CJL, Klein M. The mechanics of breathing in children with acute severe croup. Intensive Care Med 2008; 34: 324-332.

5. Kemper KJ, Benson MS, Bishop MJ. Interobserver variability in assessing pediatric postextubation stridor. Clin Pediatr (Phila) 1992; 31: 405-408.

6. Johnson DW, Jacobson S, Edney PC, Hadfield P, Mundy ME, Schuh S. A comparison of nebulized budesonide, intramuscular dexamethasone, and placebo for moderately severe croup. N Engl J Med 1998; 339: 498-503.

7. Deakers TW, Reynolds G, Stretton M, Newth CJ. Cuffed endotracheal tubes in pediatric intensive care. J Pediatr 1994; 125: 57-62.

8. Newth CJI, Rachman B, Patel N, Hammer J. The use of cuffed versus uncuffed endotracheal tubes in pediatric intensive care. J Pediatr 2004; 144: 333-337. 